\title{
Rare association between atrial septal defect and unicuspid mitral valve: Case report
}

\author{
Nilda Espinola-Zavaleta ${ }^{1,2 \#}$, Rodrigo Escalante-Armenta ${ }^{1,3 *}$, Luis Javier Castellanos-Vizcaino ${ }^{1,4}$ and Erick Alexanderson-Rosas $^{1,5 *}$ \\ ${ }^{1}$ Department of Nuclear Cardiology, National Institute of Cardiology Ignacio Chavez, Mexico City, Mexico \\ ${ }^{2}$ Department of Echocardiography, ABC Medical Center, I.A.P, Mexico City, Mexico \\ ${ }^{3}$ Mexican Faculty of Medicine, University La Salle, Mexico City, Mexico \\ ${ }^{4}$ Faculty of Health Sciences. Universidad Anahuac Mexico, State of Mexico, Mexico \\ ${ }^{5}$ Department of Physiology, Faculty of Medicine, National Autonomous University of Mexico, Mexico City, Mexico \\ \#Equal contribution
}

\begin{abstract}
The association between interatrial communication and unicuspid mitral valve is extremely unusual. We present a case of 50-year-old woman with ostium secundum atrial septal defect and unicuspid mitral valve with mild mitral regurgitation. The shape, size and borders of the interatrial septal defect and mitral valve were well characterized by 3-D transesophageal echocardiogram.
\end{abstract}

\section{Introduction}

The absence of the posterior leaflet of the mitral valve tends to present during childhood with severe symptomatic mitral regurgitation and tends to be incompatible with life [1].

Although there have been cases described with association between atrial septal defect and mitral stenosis, known as Lutembacher syndrome, atrial septal defect cases associated with unicuspid mitral valve are exceptional [2]. The most common causes of mitral regurgitation are functional, rheumatic cardiopathy and congenital valve lesions [3].

Isolated atrial septal defect has an incidence of $1.6 / 1,000$ cases and unicuspid mitral valve itself of about $1 / 8,800$ cases in German population; however, it is thought to be less in other populations [4].

The echocardiogram is the gold standard for congenital cardiopathies diagnoses, especially on its three-dimensional modality: it allows the precise characterization of septal defects and mitral valve anatomy [5].

We present the case of a 50-year-old woman with ostium secundum atrial septal defect and unicuspid mitral valve with mild regurgitation.

\section{Case presentation}

A 50-year-old woman with no relevant personal history, who presented on 2016 with chest pain and nonproductive cough of two hours of evolution as chief complaint. On the physical examination, an S2 fixed split and a II/IV systolic murmur in pulmonic area was described, which is the reason why she was sent to our institution.

Paraclinical examination showed polyglobulia ( $\mathrm{Hb} 16.8 \mathrm{~g} / \mathrm{dL}, \mathrm{RBC}$ 6.1 millions/L) and a resting electrocardiogram with sinus rhythm, heart rate of $79 \mathrm{bpm}$, incomplete right bundle branch block and biatrial enlargement.
The transthoracic echocardiogram showed dilatation of both atria, preserved systolic function on both ventricles, with a left ventricle ejection fraction of $63 \%$, of $29 \mathrm{~mm}$ TAPSE and S wave velocity of $12 \mathrm{~cm} / \mathrm{seg}$; normal left ventricular diastolic function, mild tricuspid regurgitation, moderate pulmonary artery hypertension $(51.1 \mathrm{mmHg})$, ostium secundum atrial septal defect with a $3.02 \mathrm{~cm} \mathrm{x}$ $2.25 \mathrm{~cm}$ diameter and Qp/Qs of 3.1 and a unicuspid mitral valve with mild regurgitation.

Transesophageal echocardiogram on $2 \mathrm{D}$ and $3 \mathrm{D}$ modalities allowed to define the size, morphology and borders of the atrial septal defect (Clips 1 and 2) and characterize in precisely the mitral valve anatomy (Clip 3) on both atrial and ventricular sides (Figures 1 and 2).

Currently, the patient is in NYHA functional class I, receiving medical management with ACEIs, and is on hold for atrial septal defect closure with an Amplatzer device.

\section{Discussion}

We present the case of a fifth decade woman with an ostium secundum atrial septal defect associated with unicuspid mitral valve with mild regurgitation who is still on time for a surgical closure of the septal defect, due to the fact that the pulmonary arterial hypertension is moderate. Clinical findings and three-dimensional transesophageal

${ }^{\star}$ Correspondence to: Erick Alexanderson-Rosas, National Institute of Cardiology Ignacio Chavez Juan Badiano No 1, Colonia Sección XVI, Tlalpan P.C. 14080, Mexico City, Mexico,E-mail: alexandersonerick@gmail.com

Key words: atrial septal defect; unicuspid mitral valve; heart murmur; echocardiography

Received: October 12, 2019; Accepted: October 21, 2019; Published: November 01,2019 


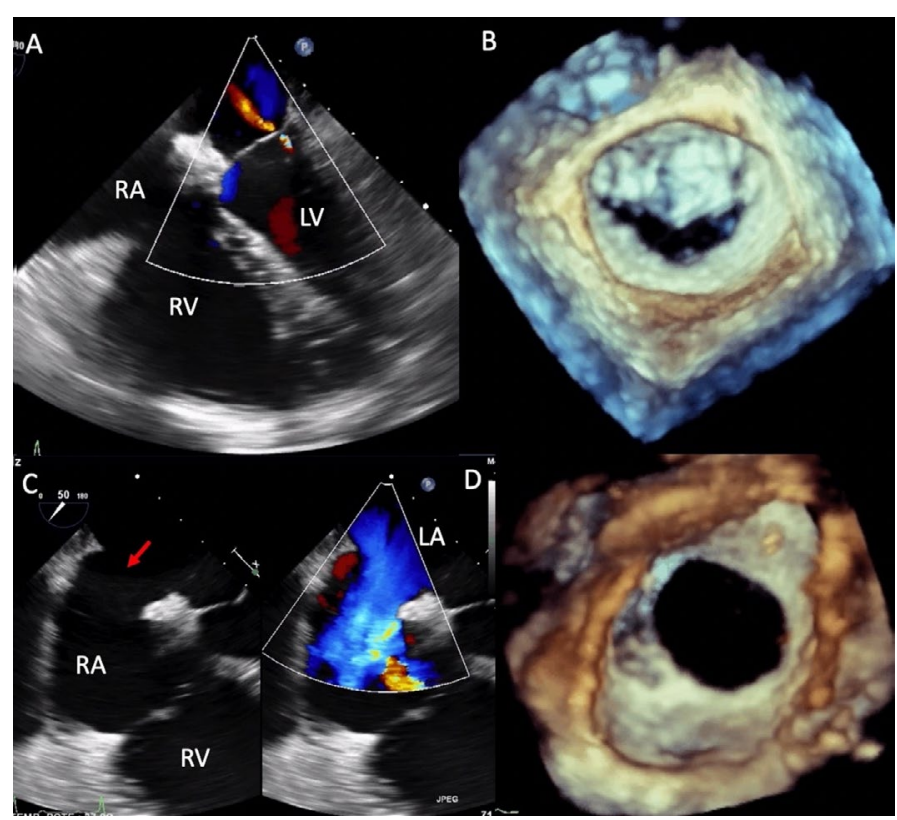

Figure 1. Transesophageal $2 \mathrm{D}$ and $3 \mathrm{D}$ echocardiogram that shows: A. Mild mitral regurgitation and dilated right cavities. B. Surgical view of the unicuspid mitral valve. C. Ostium secundum atrial septal defect (red arrow) with a left-right shunt. D. Oval shaped atrial septal defect with proper borders. Abbreviations: $\mathrm{LA}=$ left atrium, $\mathrm{LV}=$ left ventricle, $\mathrm{RA}=$ right atrium, $\mathrm{RV}=$ right ventricle

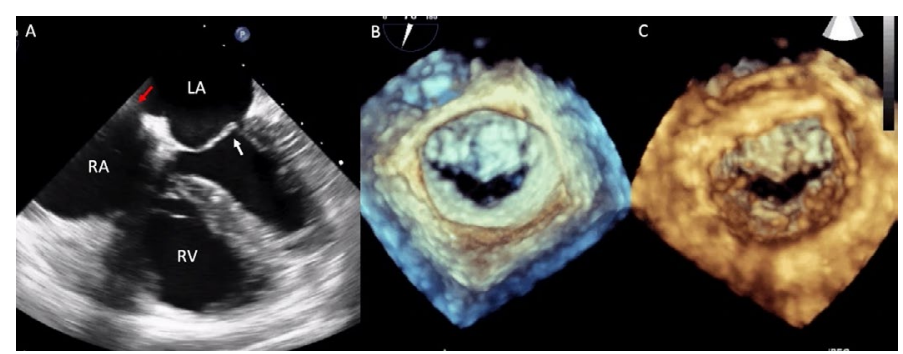

Figure 2. A. Transesophageal 2D echocardiogram showing right cavities' dilatation, red arrow points the ostium secundum atrial septal defect and white arrow points the unicuspid mitral valve. B. Surgical view of the unicuspid mitral valve. C. Ventricular view of the unicuspid mitral valve

echocardiogram were decisive for establishing the diagnosis and the therapeutic plan.

Congenital malformations present in approximately $4 / 1,000$ births, with atrial septal defect being one of the most common congenital malformations on adults [6]. There have been described cases of ostium primum atrial septal defect associated with unicuspid mitral valve because of its embryological origin [7], although there are very few cases associated with ostium secundum atrial septal defect [3]. Aplasia of the posterior leaflet of the mitral valve is associated with severe mitral regurgitation and it is usually incompatible with life without early surgical intervention [8].

Transesophageal three-dimensional echocardiogram is considered better than the bidimensional technique, seeing as it allows the precise characterization of mitral valve anatomy and of the subvalvular apparatus, as well as the size, shape and borders of the atrial septal defect [9]. For these cases, the closure of the atrial septal defect with an Amplatzer device seems to be the standard treatment, as well as mitral valve replacement when the regurgitation degree is severe [10]. Our patient is on hold for the atrial septal defect closure and will continue to be followed with annual echocardiogram of mitral valve for surveillance of the progression of mitral regurgitation.

\section{Conclusions}

Association between ostium secundum atrial septal defect and unicuspid mitral valve is very rare.

The $2 \mathrm{D}$ and $3 \mathrm{D}$ echocardiogram is the chosen technique for diagnosis and follow up of congenital cardiopathies.

\section{Highlights}

- Ostium secundum atrial septal defect is the most common congenital cardiopathy on adults.

- Unicuspid mitral valve is usually associated with severe mitral regurgitation.

- Association between ostium secundum atrial septal defect and unicuspid mitral valve is rare, and its survival rate is good as the mitral regurgitation tends to be mild.

\section{Financial support}

No financial support

\section{Conflicts of interest}

No conflict of interest between the authors.

\section{Ethical standards}

The authors assert that all procedures contributing to this work comply with the ethical standards of the relevant national guidelines on human experimentation and with the Helsinki Declaration of 1975, as revised in 2008, and has been approved by the institutional committees.

\section{References}

1. Shah J, Jain T, Shah S, Mawri S, Ananthasubramaniam K (2016) Rare Case of Unileaflet Mitral Valve. J Cardiovasc Ultrasound 24: 168-169. [Crossref]

2. Bezgin T, Elveran A, KaragÃz A, Ãanga Y, YÄlmaz F (2014) Mitral valve with a single leaflet. Turk Kardiyol Dern Ars 42: 80-82. [Crossref]

3. Hynes KM, Frye RL, Brandenburg RO, McGoon DC, Titus JL, et al. (1974) Atrial septal defect (secundum) associated with mitral regurgitation. Am J Cardiol 34: 333-338.

4. Bär H, Siegmund A, Wolf D, Hardt S, Katus HA, et al. (2009) Prevalence of asymptomatic mitral valve malformations. Clin Res Cardiol 98: 305-309. [Crossref]

5. Salustri A, Roelandt JR (1995) Ultrasonic three-dimensional reconstruction of the heart. Ultrasound Med Biol 21: 281-293.

6. Marelli AJ, Mackie AS, Ionescu-Ittu R, Rahme E, Pilote L (2007) Congenital heart disease in the general population. Circulation 115: 163-172.

7. Praagh SV, Porras D, Oppido G, Geva T, Praagh RV (2003) Cleft mitral valve withou ostium primum defect: anatomic data and surgical considerations based on 41 cases. Ann Thorac Surg 75: 1752-1762.

8. Parato VM, Masia SL (2018) Hypoplasia or Absence of Posterior Leaflet: A Rare Congenital Anomaly of The Mitral Valve in Adulthood - Case Series. J Cardiovasc Echogr 28: 45-47. [Crossref]

9. Espinola-Zavaleta N, Vargas-BarrÃ $\tilde{3}^{3} \mathrm{~J}$, Keirns C, Rivera G, Romero-CÃ $j$ rdenas A et al. (2002) Three-dimensional echocardiography in congenital malformations of the mitral valve. J Am Soc Echocardiogr 15: 468-472.

10. Narin N, Baspinar O, Pamukcu O, Sunkak S, Tuncay A, et al. (2019) Percutaneous ASD closure of children weighing less than $10 \mathrm{~kg}$. Acta Cardiol 3: 1-6. [Crossref]

Copyright: (C2019 Espinola-Zavaleta N. This is an open-access article distributed under the terms of the Creative Commons Attribution License, which permits unrestricted use, distribution, and reproduction in any medium, provided the original author and source are credited. 